\title{
Comisión de Arbitraje Médico del Estado de Yucatán y SARS-CoV-2
}

\author{
Medical Arbitration Commission of the State \\ of Yucatan and SARS-COV-2
}

Edgardo Jesús Martínez Menéndez,* Carlos Antonio Rosado Guillermoł

\begin{abstract}
RESUMEN
En 2019 se detectó en Wuhan, China un nuevo coronavirus SARS-CoV-2 que afectaba a los humanos. Padecimiento potencialmente mortal, síntomas graves, sin tratamiento ni vacuna, con incidencia mundial. El 11 de marzo 2020 la Organización Mundial de la Salud (OMS) declaró como pandemia al brote del coronavirus COVID-19. En Yucatán en marzo de 2020: Declaratoria de Emergencia. En 2020, la población del estado de Yucatán fue de 2,320,898, de esta cifra, 78\% está afiliado a algún servicio de salud. La Secretaría de Salud del Estado de Yucatán informa el primer caso de COVID-19 en marzo de 2020, en ese año se confirmaron 26,492 casos y 2,903 fallecidos; en 2021 de enero al 27 de septiembre se confirmaron 43,471 casos y 3,016 fallecidos. La Comisión de Arbitraje Médico del Estado de Yucatán (CODAMEDY) dio atención al público en 2020 y 2021. Todas las solicitudes fueron atendidas. En 2020 se obtuvo en la CODAMEDY $72 \%$ del promedio de asuntos atendidos de los últimos cinco años (331) y de enero al 27 de septiembre de 2021 se ha alcanzado 73\%. En 2020 en actividades docentes se impartieron 16 pláticas, participan 686 profesionales de la salud. En 2021 hasta el 27 de septiembre se han dictado 23 pláticas, a las cuales han asistido 589 profesionales.
\end{abstract}

Palabras clave: Comisión Nacional de Arbitraje Médico, Comisión de Arbitraje Médico del Estado de Yucatán, pandemia, COVID-19.

\begin{abstract}
In 2019, a new SARS-CoV-2 coronavirus affecting humans was detected in Wuhan, China. Life-threatening condition, severe symptoms, untreated and unvaccinated, with worldwide incidence. On March 11, 2020, WHO declared the COVID-19 coronavirus outbreak a pandemic. In Yucatan in March 2020: Emergency Declaration. In 2020, the population of the state of Yucatan was 2'320,898. 78\% are affiliated to some health service. The Secretary of Health of the State of Yucatan, reports the first case of COVID-19 in March 2020, in that year 26,492 cases were confirmed and 2,903 deaths; in 2021 from January to September 27, 43,471 cases were confirmed and 3,016 deaths. The Medical Arbitration Commission of the State of Yucatan (CODAMEDY), provided attention to the public in 2020 and 2021. All requests were met. In 2020 , CODAMEDY obtained $72 \%$ of the average number of cases handled in the last five years (331) and from January to September 27, 2021, 73\% has been reached. In 2020, in teaching activities, 16 talks were given, 686 health professionals participated. In 2021, up to September 27, 2021, 23 talks have been given, 589 professionals attended.
\end{abstract}

Keywords: National Commission of Medical Arbitration, Medical Arbitration Commission of the State of Yucatan, pandemic, COVID-19.
* Comisionado de Arbitraje Médico del Estado de Yucatán, México. ¥ Subcomisionado Médico de la Comisión de Arbitraje Médico del Estado de Yucatán, México.

\section{Correspondencia:} EJMM, codamed@ prodigy.net.mx Conflicto de intereses: No se tuvieron relaciones relevantes.

Citar como: Martínez MEJ, Rosado GCA. Comisión de Arbitraje Médico del Estado de Yucatán y SARS-CoV-2. Rev CONAMED. 2027; 26(supl. 1): s47-s50. https://dx.doi. org/10.35366/102581 Financiamiento: No se tuvieron relaciones relevantes.

Recibido: 15/10/2021. Aceptado: 15/10/2021. 


\section{INTRODUCCIÓN}

El 26 de mayo de 2000 el secretario de salud federal, el gobernador de Yucatán y el comisionado nacional de arbitraje médico atestiguaron la toma de protesta del comisionado de arbitraje médico del estado de Yucatán. La CODAMEDY inició sus trabajos con la asesoría de la CONAMED y la aplicación-en forma supletoria- de los reglamentos para la atención de quejas y demás ordenamientos de la Comisión Nacional de Arbitraje Médico. Recibió su primer caso el 1 de junio de 2000.

El 14 de julio de 2003 fue publicado en el Diario Oficial del Gobierno del Estado de Yucatán, el Decreto de Creación de la Comisión de Arbitraje Médico del Estado de Yucatán (CODAMEDY); (órgano desconcentrado de la Secretaría de Salud del Estado de Yucatán). El 04 de febrero de 2004 quedó integrado formalmente el Honorable Consejo de la CODAMEDY. El 21 de septiembre de 2004 se publicó en el Diario Oficial del Gobierno del Estado de Yucatán el reglamento interno, y el 09 de marzo de 2007, el reglamento de procedimientos para la atención de quejas médicas.

El H. Consejo de la CODAMEDY aprobó los manuales de organización, de perfil de puestos y el de políticas operativas y procesos; se complementó así el marco jurídico de la CODAMEDY.

El organigrama quedó conformado por el consejo, el comisionado, dos médicos y un abogado, un enlace administrativo y personal de apoyo en informática y secretarial.

La CODAMEDY, con su oferta de buena voluntad, imparcialidad, gratuidad, confidencialidad, crédito a la palabra y el esfuerzo para lograr conciliaciones, ofrece un matiz diferente a la sociedad; ésta es su utilidad real y es sinónimo de profesionalismo y honestidad.

La Carta Magna de los Estados Unidos Mexicanos consigna en el artículo 4.․ párrafo 4. ${ }^{\circ}$, que: «toda persona tiene derecho a la protección de la salud», por lo que el profesional de la salud deberá observar la normativa que se derive de este precepto legal en la aplicación de su metodología científica, operativa y ética para regular la atención médica que proporcione. En todo acto médico debe caber siempre la posibilidad de incurrir en una acción de responsabilidad profesional, derivada de una falta de atención a un reglamento laboral, una infracción a un ordenamiento administrativo, o bien, por la inobservancia de la norma de carácter penal. En todos estos casos las consecuencias jurídicas de la falta varían, por lo que se deberá analizar cuáles son los comportamientos del profesional de la salud en su ejercicio profesional, y en consecuencia, la probable derivación de alguna responsabilidad penal, civil o administrativa.

La queja por irregularidades en las prácticas médicas es ahora objeto de análisis e investigación, así como de propuestas y acciones preventivas que incluyen la detección de las inconsistencias del sistema de salud, la capacitación adecuada y las medidas necesarias en los eventos adversos. Están presentes las propuestas de soluciones a la queja a partir de los llamados medios alternativos de solución de controversias, como los que brindan las comisiones estatales.

En Yucatán, el H. Consejo de la CODAMEDY ha recomendado aplicar el trabajo de esta última a la conciliación y al proceso educativo asociado con el médico y el paciente.

Es en 2020 cuando de manera súbita cambian las perspectivas de salud ante la presencia del COVID. No hay sector que se encuentre fuera de esta realidad. Corresponde al sector salud en especial el afrontar retos que al presente continúan.

Se tenía la esperanza de que la pandemia estuviera bajo control al presente y no es así, a pesar del enorme progreso científico. La pandemia sigue siendo una emergencia mundial.

\section{COVID-19 Y CODAMEDY}

Se conoció por la prensa, la televisión y las redes sociales que algo sucedía con un nuevo virus que a finales del año 2019 se detectó en Wuhan, China, un nuevo coronavirus SARS-CoV-2 que afectaba a los humanos y que aumentaban los casos con rapidez; en tiempo récord la noticia cruzó fronteras al mismo tiempo que el virus, Europa después de Asia, América, África y Oceanía/Australia.

Un nuevo padecimiento del que se sabía poco, pero que era potencialmente mortal, con síntomas graves que incluían enfermedad respiratoria, sin tratamiento conocido y sin vacuna.

Esto fue lo que se supo, y nuestro país y el estado de Yucatán fueron incluidos con relativa rapidez en los listados de aquellos en los que el virus estaba 
presente; un día supimos que había sido declarado pandemia. El 11 de marzo de 2020, la OMS declaró al brote del nuevo coronavirus denominado COVID-19 como pandemia, En el estado de Yucatán el 26 de marzo de 2020 se emitió la declaratoria de emergencia. ${ }^{2}$

El país tomaba al principio un andar lento y luego desesperado ante la realidad de qué hacer con miles de casos y muertos, hospitales con limitaciones y poco que ofrecer excepto la enorme entrega y voluntad del personal de salud.

Según datos del INEGI, en 2020 la población del estado de Yucatán era de 2,320,898, de los cuales 1,181,337 son mujeres y 1,139,561 hombres, 78\% está afiliado a algún servicio de salud. ${ }^{3}$

La Secretaría de Salud del Estado de Yucatán dio a conocer que se registró el primer caso de COVID-19 el 13 de marzo de 2020, en ese año se confirmaron 26,492 casos y 2,903 fallecidos que corresponden a 10.9\% y en 2021, de enero al 27 de septiembre se confirmaron 43,471 casos y 3,016 fallecidos, porcentualmente $6.93 \%{ }^{4}$

El día a día quedaba constituido por cierres de negocios y diversiones, distanciamiento social, las personas mayores de 60 años fueron resguardadas, los cubrebocas, los lentes, el gel, la limpieza de manosy el miedo, el mismo que prevalece al presente.

A lo anterior se sumaban las patologías habituales, los cambios de la oferta médica con crisis en la atención de padecimientos.

La situación de emergencia afecta a todo incluyendo la sensación de poder estar «no presente».

El sector salud alerta y afronta el reto con los elementos que se disponen.

Se toma conocimiento del SARS-CoV-2 (COVID-19) en el momento en que el mundo se entera y cuando nuestra nación queda incluida. ¿Qué es?, ¿cómo es?, ¿cómo se previene en lo posible?, ¿medicamentos? Se ha progresado especialmente por las vacunas y se comienza a entender al virus en el ser humano.

La Comisión de Arbitraje Médico del Estado de Yucatán (CODAMEDY), como parte importante del sector, mantiene la atención al público de manera presencial en 2020 y 2021, incluso durante el semáforo rojo se crearon dos grupos de trabajo alternos que de manera presencial atendieron a los usuarios del 06 de abril al 25 de septiembre de 2020, a partir del 28 de septiembre regresó la totalidad del personal. Todas las solicitudes de la población en el ámbito de competencia de la CODAMEDY fueron atendidas.

Los tiempos de aislamiento, la limitación de la oferta de servicio en hospitales y en consultorios redundó en una disminución de los requerimientos habituales de los servicios de la CODAMEDY.

En el antecedente histórico de la CODAMEDY, de enero de 2015 a diciembre de 2019 se atendieron 1,656 asuntos ciudadanos entre orientaciones, asesorías, gestiones inmediatas y quejas, con un promedio de 331 asuntos al año. ${ }^{5}$

Durante la pandemia en el año 2020 se obtuvo en la CODAMEDY 72\% del promedio de los últimos cinco años y de enero a septiembre de 2021 se ha alcanzado 73\% faltando los últimos tres meses del año.

La CODAMEDY cuenta con 10 personas incluyendo profesionales, administrativos y manuales más el comisionado. Cuatro tuvieron COVID-19 con sitios probables de contaminación fuera del ámbito del trabajo.

Aunque de manera limitada, en el año 2020 se tuvieron actividades docentes como parte del programa operativo anual, se impartieron 16 pláticas con presencia de 686 profesionales de la salud que incluyeron los siguientes temas: «NOM 004 del expediente clínico», «Bioética y CODAMEDY», «quehacer de la CODAMEDY», «error médico», «objeción de conciencia», «calidad de la atención», «receta médica», «queja médica en consulta, medicina y calidad»y «relación médico-paciente». En 2021 de enero al 27 de septiembre se han dictado 23 pláticas sobre «aspectos legales de la medicina», «NOM 004 del expediente clínico», «relación médico-paciente», «aspectos éticos y legales en la atención a la salud», "calidad en la atención», «la queja médica», «negligencia y mala práctica médica», «integración del expediente clínico», "principales causas de la atención y funciones de la CODAMEDY», «expediente clínico, documental y electrónico», «consideraciones generales del arbitraje médico y recursos para servicio», "consentimiento informado», «bioética familiar» y «marco jurídico y administrativo de la atención médica» con asistencia de 589 profesionales.

Hay ciertos aspectos que deben ser considerados, 2020 y 2021 han sido años productivos en estudio, aprendizaje y actualización, sesiones de 
trabajo con especialistas médicos sobre COVID, aspectos legales y epidemiológicos, y se ha prodigado el estudio de la ética, bioética, derechos humanos y violencia de género.

Con mayores conocimientos sobre COVID-19 deberemos ahora completar protocolos, ponerlos en práctica al máximo, supervisar cada fase y con base en la entrega y la responsabilidad social, y en coherencia con la solidaridad que caracteriza a las comisiones, brindar el servicio con todas las precauciones que sean recomendadas por la autoridad sanitaria.

\section{CONCLUSIÓN}

La contribución a tutelar el derecho a la protección de la salud y a mejorar la calidad en la prestación de los servicios médicos debe ser una actividad permanente. Las comisiones de arbitraje médico, como instituciones especializadas que contribuyen a resolver los conflictos suscitados entre prestadores y usuarios del servicio médico, deben conservar sus altos estándares de atención aun en tiempos de pandemia.

\section{REFERENCIAS}

1. https://www.paho.org/es/noticias/11-3-2020-omscaracteriza-covid-19-como-pandemia. Revisado el 27 de septiembre de 2021.

2. Decreto $195 / 2020$ por el que se emite la declaratoria de emergencia con motivo del alto riesgo generado por la pandemia de COVID-19 (coronavirus) en el Estado de Yucatán. Disponible en: https://www.yucatan.gob.mx/ gobierno/diario_oficial.php?f=2020-3-26

3. Panorama Sociodemográfico de Yucatán 2020, p. 14. Disponible en: https://www.inegi.org.mx/contenidos/ productos/prod_serv/contenidos/espanol/bvinegi/ productos/nueva_estruc/702825198046.pdf

4. Cobierno del Estado de Yucatán, Comunicados de la Secretaría de Salud. Disponible en: https://coronavirus. yucatan.gob.mx/

5. Informes Anuales Comisión de Arbitraje Médico del Estado de Yucatán. Disponible en: http://codamedy.ssy.gob.mx/ categoria/informes/

\section{www.medigraphic.org.mx}

